\title{
Retinal Region of Polarization Sensitivity Switches during Ontogeny of Rainbow Trout
}

\author{
Shai Sabbah, ${ }^{1}$ Maheen F. Habib-Nayany, ${ }^{1}$ Zahra Dargaei, ${ }^{1}$ Frances E. Hauser, ${ }^{1}$ Maarten Kamermans, ${ }^{3,4}$ \\ and Craig W. Hawryshyn ${ }^{1,2}$ \\ ${ }^{1}$ Department of Biology and 2Centre for Neuroscience Studies, Queen's University, Kingston, Ontario, K7L 3N6, Canada, ${ }^{3}$ Research Unit Retinal Signal \\ Processing, The Netherlands Institute for Neuroscience, 1105 BA, Amsterdam, The Netherlands, and ${ }^{4}$ Department of Neurogenetics, Academic Medical \\ Center, University of Amsterdam, 1012 WX, Amsterdam, The Netherlands
}

Polarization sensitivity (PS) in vertebrate vision is controversial, perhaps because its underlying mechanism has remained obscure. An issue that might have added to the controversy is that rainbow trout (Oncorhynchus mykiss), which have served as the primary model system for polarization-based orientation, lose their ability to orient relative to celestial polarized-light patterns when parr (fry) transform into migratory smolts (juveniles), which would benefit most from polarization-based orientation. Here we addressed two key questions: (1) what is the mechanism underling PS?, and (2) how can the paradoxical loss of PS in trout smolts be reconciled? We assessed PS from optic nerve recordings in parr and smolts and found that the retinal region with enhanced PS shifted from the ventral retina in parr to the dorsal retina in smolts. This adaptation may allow fish to use the most reliable polarization field encountered at each life stage, the celestial polarization field in the shallow-swimming parr and the depth-insensitive underwater polarization field in the deepswimming smolts. In addition, we assessed spectral sensitivity across the retina and during ontogeny and fit a cascade retinal model to PS data. We found that differential contribution of two cone detectors with orthogonal PS could drive the variation in PS and that feedback from horizontal cells to cones could explain the differential amplification of PS. This elegant arrangement, in which weak PS of cones is amplified and tuned by retinal networks, allows for PS without interfering with sampling of other visual information and illustrates how sensory systems may simultaneously process disparate aspects of physical environments.

\section{Introduction}

Although sensitivity to linearly polarized light has been demonstrated in fish and, to a lesser extent, in birds (Horváth and Varjú (2004); Sabbah et al. (2005); Hawryshyn (2010)), polarization sensitivity (PS) in vertebrates and its underlying mechanism remains a subject of debate. In fish, polarized-light cues aid in foraging (Flamarique and Browman, 2001; Hawryshyn et al., 2003) and orientation (Groot, 1965; Forward and Waterman, 1973; Kleerekoper et al., 1973; Hawryshyn and Bolger, 1990; Hawryshyn et al., 1990). Ironically, trout (Oncorhynchus mykiss), which have served as the primary study species, lose their polarization-based orientation capabilities upon smoltification, when parr (fry) transform into migratory smolts (juveniles) (Hawryshyn et al., 1990). Smolts generally migrate from freshwa-

\footnotetext{
Received Dec. 13, 2012; revised March 11, 2013; accepted March 16, 2013.

Author contributions: S.S. and C.W.H. designed research;S.S., M.F.H.-N., Z.D., and F.E.H. performed research; S.S. and M.F.H.-N. analyzed data; S.S. and M.K. wrote the paper.

This research was supported by the Natural Sciences and Engineering Research Council of Canada (NSERC; Discovery Grant \#106102-07 and Research Tools and Instrumentation Grant \#359714-2008), Canada Foundation for Innovation, Ontario Innovation Trust (Grant \#202821), and the Canada Research Chair Program (to C.W.H.). S.S. was supported by a Vanier Canada Graduate Scholarship from NSERC. We thank James Fraser, Itamar Blum, Tice Post, and Ron Kerr for help in designing and fabricating the beam splitter apparatus and various components of the electrophysiology rig.

The authors declare no competing financial interests.

Correspondence should be addressed to Shai Sabbah, Department of Neuroscience, Brown University, Providence, RI 02912. E-mail:shai_sabbah@brown.edu.

DOI:10.1523/JNEUROSCI.5815-12.2013

Copyright $\odot 2013$ the authors $\quad 0270-6474 / 13 / 337428-11 \$ 15.00 / 0$
}

ter through thousands of kilometers of ocean to their feeding areas (in anadromous populations, they are known as steelhead trout) or perform extensive excursions between deep freshwater feeding grounds (in land-locked populations, they are known as rainbow trout) (Brannon and Salo, 1981). This migratory behavior (especially upon entering estuaries and near shore regions in anadromous populations) would benefit from the ability to orient relative to natural polarized light patterns, an ability seemingly lacking in smolts. Interestingly, previous studies measured the orientation responses of trout to polarized light stimuli that arrived from above and mainly illuminated the ventral retina (Hawryshyn and Bolger, 1990; Hawryshyn et al., 1990; Degner and Hawryshyn, 2001; Parkyn et al., 2003), suggesting no PS in the ventral retina of smolts. Is it possible that smolts are capable of PS via their dorsal rather than the ventral retina and, if so, what mechanism would allow such an ontogenetic change in PS?

Rainbow trout use two linear polarization detectors that show PS functions (sensitivity vs $e$-vector $[\mathrm{eV}]$ orientation) with a period of $180^{\circ}$ (Parkyn and Hawryshyn, 1993): the ultravioletsensitive cone (UVS) that is maximally sensitive to vertical polarization, and the medium/long wavelength-sensitive cone (MWS/LWS) that is maximally sensitive to horizontal polarization (Parkyn and Hawryshyn, 2000). Interaction of the two pathways produces PS functions with shorter periods (Parkyn and Hawryshyn, 2000) and was suggested to code $\mathrm{eV}$ information in the UV region, where the two cone detectors show overlapping sensitivity (through the $\alpha$-band of UVS and the $\beta$-band of MWS/ 
A
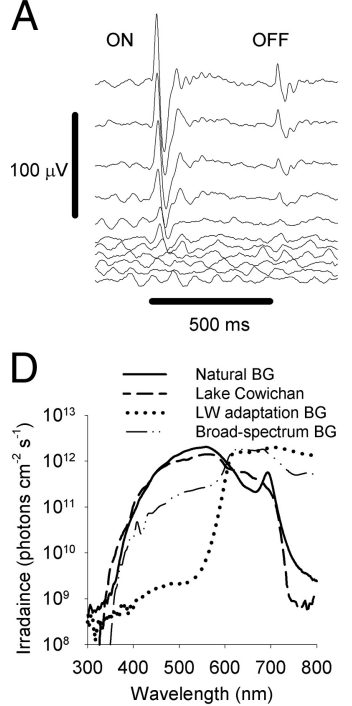

$\mathrm{B}$

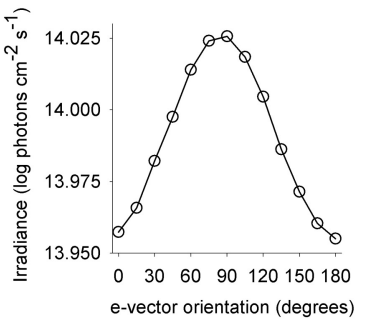

C

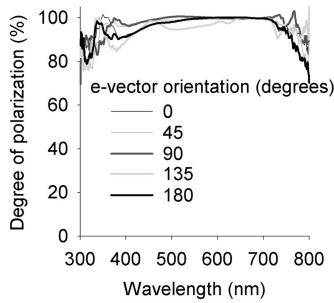

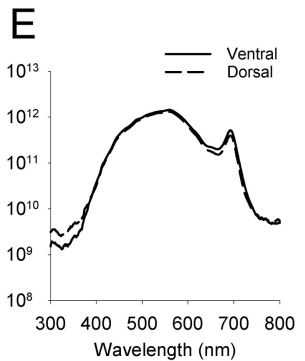

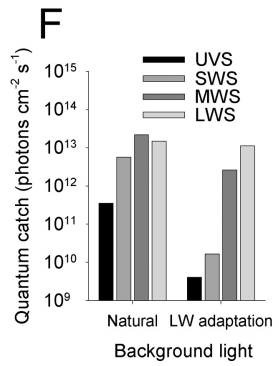

Figure 1. Response of the optic nerve, irradiance and degree of polarization of light stimuli, background illumination conditions, and quantum catch of cone pigments in rainbow trout. $A$, Response of the optic nerve to the onset and offset of light stimuli. Intensity was incremented in $0.3 \log$ unit steps and spanned a 3-log unit difference (11 intensities). Individual waveforms are displaced along the response (ordinate) axis for clarity. The duration of the stimulus is indicated by the horizontal thick line. $\boldsymbol{B}$, The stimulus irradiance at a wavelength of $360 \mathrm{~nm}$ differed slightly (13.95-14.02 log photons $\mathrm{cm}^{-2} \mathrm{~s}^{-1}$ ) between eVs showing maximum irradiance at $\mathrm{eV} 90^{\circ}$ and minimum irradiance at $\mathrm{eV} 0^{\circ}$ and $180^{\circ}$. This variation in irradiance was created by the specific angularity of the monochromator's grating that produced the narrow spectral bandwidth light stimuli. PS estimates were corrected for this variation in irradiance. Similar eV dependence was observed for the stimulus irradiance at a wavelength of $620 \mathrm{~nm}$ (14.14-14.31 log photons $\mathrm{cm}^{-2} \mathrm{~s}^{-1}$ ) and PS estimates were corrected accordingly. C, Degree of polarization for five key eVs. The degree of polarization and its dependence on wavelength were similar at the various eVs. $\boldsymbol{D}$, Three background (BG) illumination conditions were used, a broad-spectrum background, a natural background, and a LW adaptation background. The broadspectrum background was used in preliminarily experiments that included PS measurements only from the ventral retina (Fig. 2). The natural background simulated the fish natural photic environment by reproducing the sideward irradiance measured at a depth of $3 \mathrm{~m}$ at Lake Cowichan, Vancouver Island, BC, Canada (rms error $=0.36 \log$ photons $\mathrm{cm}^{-2} \mathrm{~s}^{-1}$; Pearson $r=0.96$ ). The LW adaptation background dampened the sensitivity of the LWS cone pathway. $E$, The intensity and spectrum of background irradiance (in this case, the natural background) was similar for the measurements of dorsal and ventral sensitivity. $F$, The number of photons collected by the various cone pigments under the natural and LW adaptation backgrounds, as estimated using a quantum catch (QC) model. $\mathbf{G}$, The ratio between the QC of pigments under the LW adaptation and natural backgrounds was highest for LWS, indicating that LWS is the pigment being adapted most extensively under the LW adaptation compared with the natural background.

LWS; Coughlin and Hawryshyn, 1995). Moreover, feedback from retinal interneurons such as horizontal cells (HCs) has been suggested to shape PS further (Ramsden et al., 2008). However, it remains largely unknown how differential contribution of cone detectors and $\mathrm{HC}$ - cone feedback tune PS.

Here we addressed two unresolved key questions: (1) what is the mechanism underling PS in vertebrates?, and (2) how can the paradoxical loss of PS in trout smolts be reconciled? We measured PS from the optic nerve of rainbow trout parr and smolts for the dorsal and ventral retina separately. We found an ontogenetic switch of enhanced PS from the ventral to the dorsal retina. Moreover, measuring spectral sensitivity and fitting a cascade retinal model to PS data revealed that differential contribution of two cone detectors with orthogonal PS and HC-cone feedback could largely explain the variation observed in PS across retinal regions and life stages.

\section{Materials and Methods}

Fish care and preparation. Parr $(17 \pm 4.3 \mathrm{~g})$ and smolt $(70 \pm 12 \mathrm{~g})$ rainbow trout (Onchorynchus mykiss strain Kamloop; Rainbow Springs Trout Hatchery) were held in our aquatic facility under a $12 \mathrm{~h}$ light: $12 \mathrm{~h}$ dark photoperiod of full-spectrum illumination (BlueMax fluorescent lamps; Full Spectrum Solutions) at a temperature of $15 \pm 1^{\circ} \mathrm{C}$. Fish were fed $2 \mathrm{~mm}$ trout pellets (Martin Mills) once daily.

To estimate spectral sensitivity and PS, compound action potentials (CAPs) were recorded from the optic nerve of the fish. Before recordings, fish were immersed in a solution of $125 \mathrm{mg} \mathrm{L}^{-1}$ tricaine methanesulfonate (MS-222) until they reached stage III anesthesia (Sabbah et al., 2012). A general anesthetic (metomidate hydrochloride, $0.3 \mathrm{mg} \mathrm{g}^{-1}$ body mass; Syndel Laboratories) and an immobilizing agent (pancuronium bromide, $0.05 \mathrm{mg} \mathrm{g}^{-1}$ body mass; Conier Chem and Pharma) were injected subcutaneously. Test fish were placed in a holding cradle in a Faraday cage and irrigated with aerated fresh water (temperature $15 \pm$ $1^{\circ} \mathrm{C}$, flow rate $\left.0.2-0.6 \mathrm{~L} \mathrm{~min}^{-1}\right)$. All experimental and animal care procedures were approved by Queen's University Animal Care Committee under the auspices of the Canadian Council for Animal Care.

CAP experimental apparatus. The optical system and recording apparatus for CAP measurement have been described in detail previously (Parkyn and Hawryshyn, 2000; Hawryshyn et al., 2003). Two background channels using 250 $\mathrm{W}$ halogen lamps (24 V ELC; Eiko) provided constant background illumination to light adapt the eye. A bifurcated optical fiber (fused silica, numerical aperture 0.22; Fiberoptic Systems) guided light from the two background channels to the electrophysiology rig. The intensity and spectral composition of background illumination were manipulated using interference cutoff filters and neutral density filters (Corion) and any inherent polarization was removed using a ground glass diffuser (fused silica; Thorlabs).

The stimulus channel used a $150 \mathrm{~W}$ xenon arc lamp and a monochromator (Photon Technology International), a $0-2.7$ optical density (OD) neutral density wedge (fused silica; Melles-Griot), a filter wheel featuring 9 neutral density filters of $0-4.0 \mathrm{OD}$ at $0.5 \mathrm{OD}$ increments, and an electronic shutter (UniBlitz D122; Vincent Associates). These components were used to manipulate the wavelength, intensity, and duration of the stimulus. An optical fiber (fused silica, NA 0.55; Fiberoptic Systems) guided light from the stimulus channel to the electrophysiology rig.

The background and stimulus optical fibers were fitted to a polka-dot beam splitter (fused silica; Thorlabs) and an array of UV-visible transmissive lenses to produce a stimulus beam (diameter $0.5 \mathrm{~cm}$ at the plane of the fish eye) contained within the background beam (diameter $1 \mathrm{~cm}$ ). For PS measurements, a UV-visible linear polarizer ( $\mathrm{HNP}^{\prime} \mathrm{B}$, Polaroid) was mounted over the stimulus channel optical fiber to linearly polarize the light stimulus. The irradiance of the stimulus differed slightly across eVs (Fig. 1B); estimates of PS were corrected for this variation in irradiance. The degree of polarization and its dependence on wavelength were similar at the various eVs, calculated as described previously (Wolff and Andreou, 1995; Sabbah and Shashar, 2006; Fig. 1C).

$C A P$ recording procedure. Before CAP recordings, the dermis and bone over the left optic tectum were removed using a surgical drill and a Teflon-coated chlorided silver electrode $(0.5 \mathrm{~mm}$; A-M Systems) was inserted into the lumen of the optic nerve (Parkyn and Hawryshyn, 1993, 2000). A ground electrode was placed on the caudal fin and a reference electrode (Teflon-coated chlorided silver electrode) was placed on the skull. To ensure proper placement of the recording electrode, the shape and latency characteristics of the observed waveform were compared for different electrode penetrations. A typical waveform of the optic nerve consists of an initial depolarization phase representing the response of ON ganglion cells (GCs) to the onset of light (the ON response, which occurs at most 64 ms after the stimulus; Parkyn and Hawryshyn, 2000), 
followed by another depolarization phase representing the response of OFF GCs to the offset of light (the OFF response; Fig. 1A).

The duration of the light stimulus was $500 \mathrm{~ms}$ with an interstimulus interval of 5 s. A BMA-200 bioamplifier (CWE) amplified (gain 2000) and filtered (5 Hz low-pass; $100 \mathrm{~Hz}$ high-pass) the CAP signal. The signal was digitized with a 16-bit A/D data acquisition system (Micro 1401; Cambridge Electronic Design) and the amplitude of the ON response (in microvolts) was measured using Signal 4 data acquisition software.

Spectral sensitivity was measured in $10 \mathrm{~nm}$ increments, from 340 to $700 \mathrm{~nm}$, in a staggered wavelength presentation to prevent adaptation to specific spectral regions. At each wavelength, the ON response to 11 stimulus intensities (irradiance levels) was determined. PS was measured in $\mathrm{eV}$ increments of $15^{\circ}$, from $0^{\circ}$ to $180^{\circ}$, in a staggered $\mathrm{eV}$ presentation at a wavelength of either 360 or $620 \mathrm{~nm}$. At each eV, the ON response to 11 stimulus intensities was determined.

Spectral sensitivity and PS of both the ventral and the dorsal retina were measured separately in parr and smolts. To measure the sensitivity of the ventral retina, the stimulus and background light illuminated the eye at an angle of $45^{\circ}$ from above, at a distance of $5 \mathrm{~cm}$. In contrast, to measure the sensitivity of the dorsal retina, the stimulus and background light illuminated the eye at an angle of $45^{\circ}$ from below. To ensure that the geometry of the incoming light relative to the position of the eye remained constant, the beam splitter apparatus (delivering the background and stimulus light) was positioned at either of two fixed points on a semicircular track. To reduce any light incident on undesirable regions of the retina, a black opaque patch blocked either the ventral half of the cornea (for the measurement of sensitivity of the ventral retina) or the dorsal half of the cornea (for the measurement of sensitivity of the dorsal retina).

Analysis of CAP responses. A third-order polynomial was fit to the response versus irradiance curve and the threshold irradiance that corresponded to a fixed response criterion was interpolated; sensitivity was estimated as the reciprocal of this threshold irradiance (Sabbah et al., 2012). The response criterion was set to $\sim 50 \%$ of maximum response, which corresponded to response criteria of $30 \mu \mathrm{V}$ (for PS) and $12 \mu \mathrm{V}$ (for spectral sensitivity). The response criterion was kept uniform for all wavelengths (spectral sensitivity) and eVs (PS). Log relative sensitivity curves were created by normalizing the log absolute sensitivity values to the maximum sensitivity across the spectrum (spectral sensitivity; Sabbah et al., 2010) and across eVs (PS).

Background illumination conditions. An unpolarized background light beam adapted the fish eye 30 min before the measurement and during the measurement of either spectral sensitivity or PS. Measurements were conducted under three different light backgrounds: (1) a broadspectrum background that was used in preliminarily experiments that included PS measurements only from the ventral retina; (2) a natural background that simulated the fishes' natural photic environment by reproducing the sideward irradiance measured at a depth of $3 \mathrm{~m}$ at Lake Cowichan, Vancouver Island, BC, Canada (Flamarique et al., 1992); and (3) an LW adaptation background that dampened the sensitivity of the LWS cone pathway. The irradiance provided under the various background conditions was measured at the plane of the fish eye using a spectroradiometer (QE65000; Ocean Optics) connected to an optical fiber (QP600-2-UV/VIS; Ocean Optics) that was fitted with a cosine corrector (CC-3-UV; Ocean Optics). The spectroradiometer setup was calibrated for absolute irradiance as described previously (Sabbah et al., 2011). The intensity and spectrum of background irradiance were similar for the measurements of dorsal and ventral sensitivity (Fig. 1E). The number of photons collected by the various cone pigments under the natural and LW adaptation backgrounds was estimated using a quantum catch model as follows:

$$
Q_{i}=\sum_{\lambda=300}^{800} A_{i}^{\prime}(\lambda) T(\lambda) E(\lambda)
$$

where $Q_{i}$ denotes the quantum catch of cone pigment $i, A^{\prime}{ }_{i}(\lambda)$ denotes the spectral absorbtance of cone pigment $i, T(\lambda)$ denotes the normalized (ranging 0 to 1 ) spectral transmission of the ocular media (approximated by the transmission of the lens [Hawryshyn et al., 1989] and measured as described previously [Sabbah et al., 2012]), and $E(\lambda)$ denotes the spectral photon irradiance of the background (Fig. $1 F, G$ ). Absorbtance spectra $A^{\prime}(\lambda)$ were estimated as follows:

$$
A^{\prime}(\lambda)=1-10^{-A(\lambda)(l)(s)}
$$

where $A(\lambda)$ denotes the spectral absorbance of the cone pigment, $S$ denotes the transverse specific density of each cone type, and $l$ denotes the outer segment length of each cone type ( $S$ and $l$ values were obtained from previous reports; Hawryshyn and Hárosi, 1994 and Cheng et al., 2006, respectively). Absorbance spectra were generated as described previously (Govardovskii et al., 2000) for the four cone pigments reported in rainbow trout. The $\lambda_{\max }$ of visual pigments with an $\mathrm{A}_{1}$ chromophore were as follows: UVS, $365 \mathrm{~nm}$; SWS, $434 \mathrm{~nm}$; MWS, $531 \mathrm{~nm}$; and LWS, $576 \mathrm{~nm}$ (Browman and Hawryshyn, 1992; Hawryshyn and Hárosi, 1994). Absorbance spectra were generated while assuming visual pigments exhibiting mixed chromophore retina: equal proportions of $A_{1}$ (retinal) and $A_{2}$ (3,4-dehydroretinal) chromophore. The $\lambda_{\max }$ shift associated with changes in chromophore composition was accounted for when generating the absorbance spectra (Hárosi, 1994).

Cascade retinal model for PS. The retinal model was modified from an earlier one (Kamermans and Hawryshyn, 2011). The model assumes two classes of cones, one acting as a vertical polarization detector $\left(P_{\mathrm{v}}\right)$ and the other acting as a horizontal polarization detector $\left(P_{\mathrm{h}}\right)$. The total activity of horizontal cells $\left(I_{\mathrm{HC}}\right)$ is the sum of the horizontal and vertical detector inputs received from the cones. Because the input to HCs is nonlinear, HCs show slight $\mathrm{eV}$ tuning. The output of HCs is subtracted from the output of the cones, and this difference signal is amplified and sent to the bipolar cells (BCs). The horizontal and vertical detector inputs to the various BC classes are assumed to generate nonopponent and opponent pathways, just as for color vision (Baylor et al., 1971). These nonopponent and opponent pathways arise from linear combinations of BCs with orthogonal (horizontal or vertical) eVs. For simplicity, the model accounts for the global activity generated by all ON-BCs; these signals are sent to the GCs. CAP as measured in this study consists of integrated spike activity of GCs. Spikes are generated by depolarization but not by hyperpolarization. Therefore, $\mathrm{BC}$ signals are rectified, leading to $\mathrm{ON}$ and OFF responses. Finally, because here we have analyzed only the ONCAP responses, we ignore the OFF-CAP responses in the model.

The model takes the following mathematical form:

For cones:

$$
\begin{gathered}
P_{\mathrm{v}}=K_{\mathrm{Pv}} \cdot \log \left[1+\cos ^{2}(\theta)\right] \\
\text { and } P_{\mathrm{h}}=K_{\mathrm{Ph}} \cdot \log \left[1+\sin ^{2}(\theta)\right] .
\end{gathered}
$$

For HCs:

$$
\begin{gathered}
I_{\mathrm{HC}}=P_{\mathrm{v}}+P_{\mathrm{h}} \\
\text { and } \mathrm{HC}=\frac{I_{\mathrm{HC}}}{I_{\mathrm{HC}}+K}+B .
\end{gathered}
$$

For BCs:

$$
\begin{gathered}
\mathrm{BC}_{\mathrm{v}}=P_{\mathrm{v}}-\mathrm{HC} \cdot \mathrm{C} \\
\text { and } \mathrm{BC}_{\mathrm{h}}=P_{\mathrm{h}}-\mathrm{HC} \cdot C .
\end{gathered}
$$

For GCs:

$$
\begin{gathered}
\mathrm{GC}_{\mathrm{v}}=\mathrm{BC}_{\mathrm{v}} \text { if } \mathrm{BC}_{\mathrm{v}}>0, \\
\mathrm{GC}_{\mathrm{v}}=0 \text { if } \mathrm{BC}_{\mathrm{v}}<0, \\
\mathrm{GC}_{\mathrm{h}}=\mathrm{BC}_{\mathrm{h}} \text { if } \mathrm{BC}_{\mathrm{h}}>0, \\
\text { and } \mathrm{GC}_{\mathrm{h}}=0 \text { if } \mathrm{BC}_{\mathrm{h}}<0
\end{gathered}
$$

For CAPs:

$$
\mathrm{CAP}=\mathrm{GC}_{\mathrm{v}}+\mathrm{GC}_{\mathrm{h}}
$$



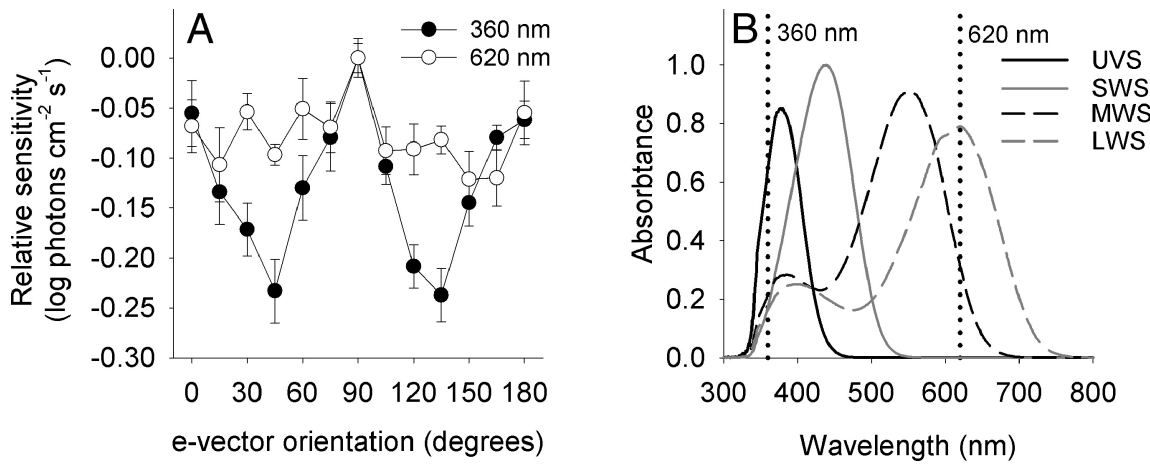

Figure 2. Interaction of the UVS and MWS/LWS pathways in rainbow trout encodes $\mathrm{eV}$ information in the UV region. $\boldsymbol{A}$, PS measured from the ventral retina of parr with stimulus wavelengths of 360 and $620 \mathrm{~nm}$. PS measured with a stimulus of $360 \mathrm{~nm}$ showed a w-shaped PSF, representing the contributions of the UVS pathway $\left(\mathrm{eV} 0^{\circ}, 180^{\circ}\right)$ and the MWS/LWS pathway $\left(\mathrm{eV} 90^{\circ}\right)$. In contrast, PS measured with a stimulus of $620 \mathrm{~nm}$ showed PSF with a maximum at $\mathrm{eV} 90^{\circ}$ and an amplitude significantly smaller than with the $360 \mathrm{~nm}$ stimulus (see Results for statistics). Error bars indicate \pm 1 SEM. Sample size, $360 \mathrm{~nm}: n=6,620 \mathrm{~nm}: n=$ 5. $\boldsymbol{B}$, Absorbtance spectra of the cone pigment classes in rainbow trout constructed while assuming visual pigments exhibiting an $\mathrm{A}_{2}$ chromophore proportion of 0.5 . The spectral location of the 360 and $620 \mathrm{~nm}$ stimuli are indicated by dotted vertical lines.

Where $K_{\mathrm{Pv}}$ and $K_{\mathrm{Ph}}$ denote the weight of the vertical and horizontal detectors, respectively, $B$ denotes the offset of HCs, $C$ denotes the feedback strength from HCs to cones, and $K$ denotes the half-maximum activation of the sigmoidal function that describes the HC membrane potential. The model was least-squares fit to data using $\mathrm{R}$ version 2.15.0 (R Development Core Team, 2012).

Statistical analysis. The amplitude of PS functions and the LWS:UVS cone contribution ratio to spectral sensitivity most often did not follow normal distribution (Kolmogorov-Smirnov test; test statistic, $D ; \alpha=$ 0.05 ) and their variance differed across treatment groups (Levene's test; test statistic, $W ; \alpha=0.05$ ). Test statistics were described in detail previously (Sokal and Rohlf, 1995. To examine how these indices varied between life stages, retinal regions, and background conditions, we used a randomization test, with the difference between the indices' means of any two treatment groups as a test statistic. The observed test statistic was compared with the null distribution, and the $p$-value was calculated ( $\alpha=$ 0.05 ). The null distribution was estimated from 10,000 replicates of the difference between the indices' means of any two groups that were established by randomly permuting the indices' values while maintaining the original group sizes (Edgington, 1995). In addition, to provide the central tendency and a measure of variation of the amplitude of PS functions, the amplitude of each PS function in a given treatment group was calculated, and the average \pm SD amplitude for that group is reported. A similar procedure was used for providing the average \pm SD of the LWS:UVS cone contribution ratio to spectral sensitivity. Statistical analysis was performed using R version 2.15.0.

\section{Results}

\section{Interaction of the UVS and MWS/LWS detector pathways encodes $\mathrm{eV}$ information in the $\mathrm{UV}$ region}

To determine whether PS depends on UV light, we recorded CAPs from the optic nerve of rainbow trout parr in response to linearly polarized stimuli at wavelengths of 360 and $620 \mathrm{~nm}$ that illuminated the ventral retina. Figure 1 provides examples of CAP responses, properties of the irradiance and polarization of the light stimulus, and characterization of the broad-spectrum background illumination used.

Two aspects of PS functions (PSFs) are important to consider. First is the shape of the PSF. PS in rainbow trout is mediated by two pathways: the UVS pathway is maximally sensitive to vertical linear polarization $\left(\mathrm{eV} 0^{\circ}, 180^{\circ}\right)$, whereas the MWS/LWS pathway is maximally sensitive to horizontal linear polarization $(\mathrm{eV}$ 90 ${ }^{\circ}$ ) (Parkyn and Hawryshyn, 1993; Coughlin and Hawryshyn, 1995). Therefore, activation of at least one of the pathways would produce PSFs that show symmetry around $\mathrm{eV} 90^{\circ}$. Conversely, asymmetrical PSFs would indicate that neither of the pathways is being activated, suggesting the lack of PS. Second, the peak-to-peak amplitude of PSF, the sensitivity difference between the peak and trough of PSF (hereafter referred to as the amplitude or AMP). This amplitude describes how well PS can convey differences between $\mathrm{eVs}$ : the larger the amplitude, the better the chances of discriminating between different $\mathrm{eVs}$.

PS measured with a stimulus of 360 $\mathrm{nm}$ that excited the two cone detectors showed a typical w-shaped PSF (Fig. 2), representing the contributions of the UVS pathway (maximally sensitive to $\mathrm{eV} 0^{\circ}$, $180^{\circ}$ ) and the MWS/LWS pathway (maximally sensitive to $\mathrm{eV} 90^{\circ}$ ). In contrast, PS measured with a stimulus of $620 \mathrm{~nm}$ that excited mainly the MWS/LWS pathway showed PSF with a maximum at $\mathrm{eV} 90^{\circ}$ and an amplitude significantly smaller than with the $360 \mathrm{~nm}$ stimulus (randomization test $[\mathrm{RT}], p=0.005 ; \mathrm{AMP}_{360 \mathrm{~nm}}=$ $0.29 \pm 0.05, \mathrm{AMP}_{620 \mathrm{~nm}}=0.19 \pm 0.01$ average $\pm \mathrm{SD}$ log photons $\left.\mathrm{cm}^{-2} \mathrm{~s}^{-1} ; n_{360 \mathrm{~nm}}=6, n_{620 \mathrm{~nm}}=5\right)$. The SWS cone detector was shown previously to be insensitive to the polarization of light (Parkyn and Hawryshyn, 1993; Coughlin and Hawryshyn, 1995). Therefore, these findings are consistent with past studies (Parkyn and Hawryshyn, 1993, 2000; Ramsden et al., 2008) and indicate that interaction of the UVS and MWS/LWS pathways encodes $\mathrm{eV}$ information efficiently in the UV spectrum. Therefore, all subsequent PS measurements were conducted with UV $(360 \mathrm{~nm})$ stimuli.

\section{PS changes across the retina and during ontogeny}

To study the retinal topography and ontogeny of PS, we measured PS in the UV spectrum from the optic nerve of rainbow trout parr and smolts for the dorsal and ventral retina separately. To evaluate the feasibility of PS under natural conditions, PS was measured for the first time under background illumination that accurately mimicked the photic conditions encountered at the native environment of rainbow trout (Fig. 1D,E).

In the ventral retina, PSF amplitude was significantly larger in parr than in smolts $\left(\mathrm{RT}, p=0.002\right.$ AMP $_{\text {parr }}=0.96 \pm 0.31$, $\mathrm{AMP}_{\text {smolt }}=0.54 \pm 0.24$ average $\pm \mathrm{SD} \log$ photons $\mathrm{cm}^{-2} \mathrm{~s}^{-1}$; $n_{\text {parr }}=11, n_{\text {smolt }}=10$; Fig. 3 , black symbols). In addition, although PSF in parr showed a typical symmetric w-shape function (sensitivity peaks at $\mathrm{eV} 0^{\circ}, 90^{\circ}$, and $180^{\circ}$ ) indicative of the contribution of both pathways in forming PS, PSF in smolts did not show symmetry around $\mathrm{eV} 90^{\circ}$. Therefore, the small amplitude and lack of symmetry of PSF suggest a reduction of PS in the ventral retina upon smoltification.

In the dorsal retina, PSF amplitude in parr was significantly smaller than in smolts (RT, $p=0.043$; $\mathrm{AMP}_{\text {parr }}=0.28 \pm 0.14$, $\mathrm{AMP}_{\text {smolt }}=0.46 \pm 0.25 \log$ photons cm $\mathrm{cm}^{-2} \mathrm{~s}^{-1} ; n_{\text {parr }}=12, n_{\text {smolt }}=$ 12; Fig. 3, white symbols). In addition, PSF in parr showed a symmetric but complex shape, with secondary sensitivity peaks at $\mathrm{eV} 15^{\circ}$, $45^{\circ}, 135^{\circ}$, and $165^{\circ}$. In contrast, the shape of PSF in smolts resembled an attenuated, smaller-amplitude version of the typical $\mathrm{w}$-shaped function found in the ventral retina of parr, with sensitivity peaks at $\mathrm{eV} 0^{\circ}, 90^{\circ}$, and $180^{\circ}$.

Furthermore, in parr, PSFs were symmetric around $\mathrm{eV} 90^{\circ}$ for both the ventral and dorsal retina (Fig. $3 A$ ). However, the ampli- 
tude of PSFs was significantly larger in the ventral than in the dorsal retina (RT, $p<$ $0.001 ; \mathrm{AMP}_{\text {dorsal }}=0.28 \pm 0.14, \mathrm{AMP}_{\text {ventral }}$ $=0.96 \pm 0.31 \log$ photons $\mathrm{cm}^{-2} \mathrm{~s}^{-1}$; $n_{\text {dorsal }}=12, n_{\text {ventral }}=11$ ), indicating enhanced PS in the ventral retina of parr. In contrast, in smolts, PSF amplitude did not differ significantly between the ventral and dorsal retina $\left(\mathrm{RT}, p=0.308\right.$; $\mathrm{AMP}_{\mathrm{dor}^{-}}$ sal $=0.46 \pm 0.25, \mathrm{AMP}_{\text {ventral }}=0.54 \pm$ $0.24 \log$ photons $\mathrm{cm}^{-2} \mathrm{~s}^{-1} ; n_{\text {dorsal }}=12$, $\left.n_{\text {ventral }}=10\right)$. However, PSF in the dorsal retina, but not in the ventral retina, showed symmetry around $\mathrm{eV} 90^{\circ}$ (Fig. $3 B$ ), indicating enhanced PS in the dorsal retina of smolts. These data suggest an ontogenetic switch in the region of enhanced PS from the ventral retina in parr to the dorsal retina in smolts. The shape similarity of PSF in the ventral retina of parr and the dorsal retina of smolts may suggest similarity in the mechanism mediating PS.

Effect of modulation of background illumination on PS $P S$ in the ventral retina of parr and the dorsal retina of smolts react similarly to background modulation

To gain insight into the mechanism underlying PS, we studied how PS is modulated under different light backgrounds. We remeasured PS, but under background illumination that selectively adapted the LWS cone (LW adaptation background; Figure $1 D, F, G)$. The shape of PSFs in the ventral retina of parr and the dorsal retina of smolts varied similarly in response to background modulation (Fig. 4A, D). In both cases, PSFs measured under the natural background followed a typical w-shape, whereas PSF measured under the LW adaptation background showed a sensitivity dip around $\mathrm{eV} 90^{\circ}$. These sensitivity changes were in agreement with our expectations based on the PS of the UVS and MWS/LWS pathways in isolation: that is, in both retina regions, sensitivity was depressed at $\mathrm{eV} 90^{\circ}$ under the LW adaptation background that selectively adapted the LWS cone and pronounced at $\mathrm{eV} 0^{\circ}, 90^{\circ}$, and $180^{\circ}$ under the natural background that adapted the various cone classes more equally. However, the amplitude of PSFs in the dorsal retina of smolt was significantly smaller than in the ventral retina of parr, at least under the natural background (RT, natural: $p<0.001 ; \mathrm{AMP}_{\text {parr-ventral }}=$ $0.96 \pm 0.31, \mathrm{AMP}_{\text {smolt-dorsal }}=0.46 \pm 0.25 \log$ photons $\mathrm{cm}^{-2}$ $\mathrm{s}^{-1} ; n_{\text {parr-ventral }}=11, n_{\text {smolt-dorsal }}=12 ;$ LW adaptation: $p=$ 0.092; $\mathrm{AMP}_{\text {parr-ventral }}=0.54 \pm 0.32, \mathrm{AMP}_{\text {smolt-dorsal }}=0.24 \pm$ $0.14 \log$ photons $\mathrm{cm}^{-2} \mathrm{~s}^{-1} ; n_{\text {parr-ventral }}=6, n_{\text {smolt-dorsal }}=5$ ). The reduced PS in the dorsal retina of smolts may reflect differences in the contributions of the UVS and MWS/LWS pathways. This will be described below.

$P S$ in the dorsal retina of parr and the ventral retina of smolts react minimally to background modulation

The amplitude of PSFs in the dorsal retina of parr did not differ significantly between backgrounds that varied greatly in the relative adaptation of the LWS cone $\left(\mathrm{RT}, p=0.322 ; \mathrm{AMP}_{\text {natural }}=\right.$ $0.24 \pm 0.14, \mathrm{AMP}_{\mathrm{LW} \text { adaptation }}=0.36 \pm 0.15 \log$ photons $\mathrm{cm}^{-2}$ $\mathrm{s}^{-1} ; n_{\text {naural }}=12, n_{\mathrm{LW} \text { adaptation }}=6$ ). This is in contrast to the ventral retina of parr, in which the different backgrounds produced PSFs that differed significantly in amplitude $\left(\mathrm{RT}, p=0.017\right.$; $\mathrm{AMP}_{\text {natural }}=$

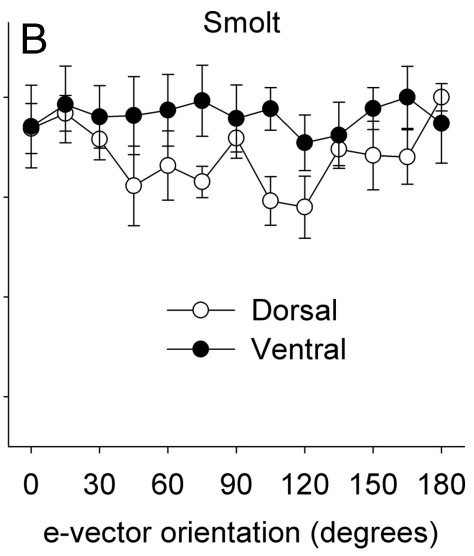

Parr

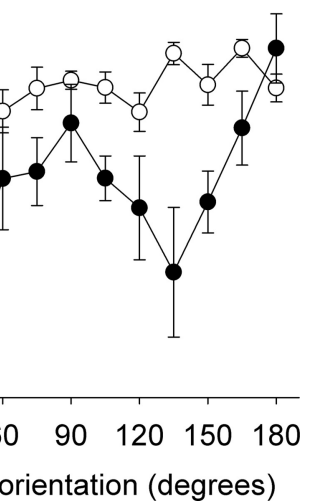

Figure 3. Topography of PS changes during ontogeny of rainbow trout. PS measured under natural background illumination W-shape, and PSF in the ventral retina of smolts did not show symmetry around eV $90^{\circ}$. Error bars indicate \pm 1 SEM. Sample size, parr-dorsal: $n=12$, parr-ventral: $n=11$, smolt-dorsal: $n=12$, smolt-ventral: $n=10$.

$0.96 \pm 0.31, \mathrm{AMP}_{\mathrm{LW} \text { adaptation }}=0.54 \pm 0.32 \log$ photons $\mathrm{cm}^{-2}$ $\left.\mathrm{s}^{-1} ; n_{\text {naural }}=11, n_{\mathrm{LW} \text { adaptation }}=6\right)$. In addition, the change in shape of PSFs in the dorsal retina of parr in response to background modulation was reminiscent of the change observed in the ventral retina, but of smaller magnitude (Fig. $4 A, C$ ). This suggests little dependence of PS in the dorsal retina of parr on the relative contributions of the UVS and MWS/LWS pathways. However, the insignificant effect of background modulation on PSF amplitude might be merely a consequence of the overall weaker PS in the dorsal retina of parr. Moreover, in the ventral retina of smolts, the different backgrounds did not produce significantly different PSF amplitudes (RT, $p=0.189 ; \mathrm{AMP}_{\text {natural }}=0.54 \pm 0.24, \mathrm{AMP}_{\mathrm{LW} \text { adaptation }}=0.36 \pm 0.13$ $\log$ photons $\left.\mathrm{cm}^{-2} \mathrm{~s}^{-1} ; n_{\text {naural }}=10, n_{\mathrm{LW} \text { adaptation }}=4\right)$ or considerably different PSF shapes (Fig. $4 B$ ). This is in contrast to the dorsal retina of smolts, in which the different backgrounds produced PSFs with similar amplitudes $\left(\mathrm{RT}, p=0.092 ; \mathrm{AMP}_{\text {natural }}=0.46 \pm 0.25\right.$, $\mathrm{AMP}_{\mathrm{LW} \text { adaptation }}=0.25 \pm 0.14 \log$ photons cm $\mathrm{cm}^{-2} \mathrm{~s}^{-1} ; n_{\text {naural }}$ $=12, n_{\mathrm{LW} \text { adaptation }}=5$ ) but with substantially different shapes (Fig. $4 D$ ). The limited effect of background modulation on PSFs, the reduced amplitude of PSFs in the dorsal relative to the ventral retina of parr, and the reduced PS in the ventral retina of smolts (described above) might be explained by different contributions of the UVS and MWS/LWS pathways. This will be described below.

\section{Effect of differential cone contribution on PS}

Contribution of the UVS and LWS pathways varies across the retina and during ontogeny

The loss of polarization-based orientation responses upon smoltification was shown previously to be associated with a mass loss of UVS cones, with retention of UVS cones only in the dorsotemporal retina (Beaudet et al., 1993; Allison et al., 2003). However, it has never been shown how this selective disappearance of UVS cones in smolts affects PS across the retina. To study the specific contributions of the UVS and LWS pathways across the retina and during ontogeny, we measured spectral sensitivity from parr and smolts for the dorsal and ventral retina separately. Relative LW sensitivity ( $\sim 640-680 \mathrm{~nm})$, which was mediated by the LWS cone, was higher in the ventral than in the dorsal retina for both parr and smolts and under both backgrounds. In addition, both the dorsal and ventral retina of parr, but only the dorsal 

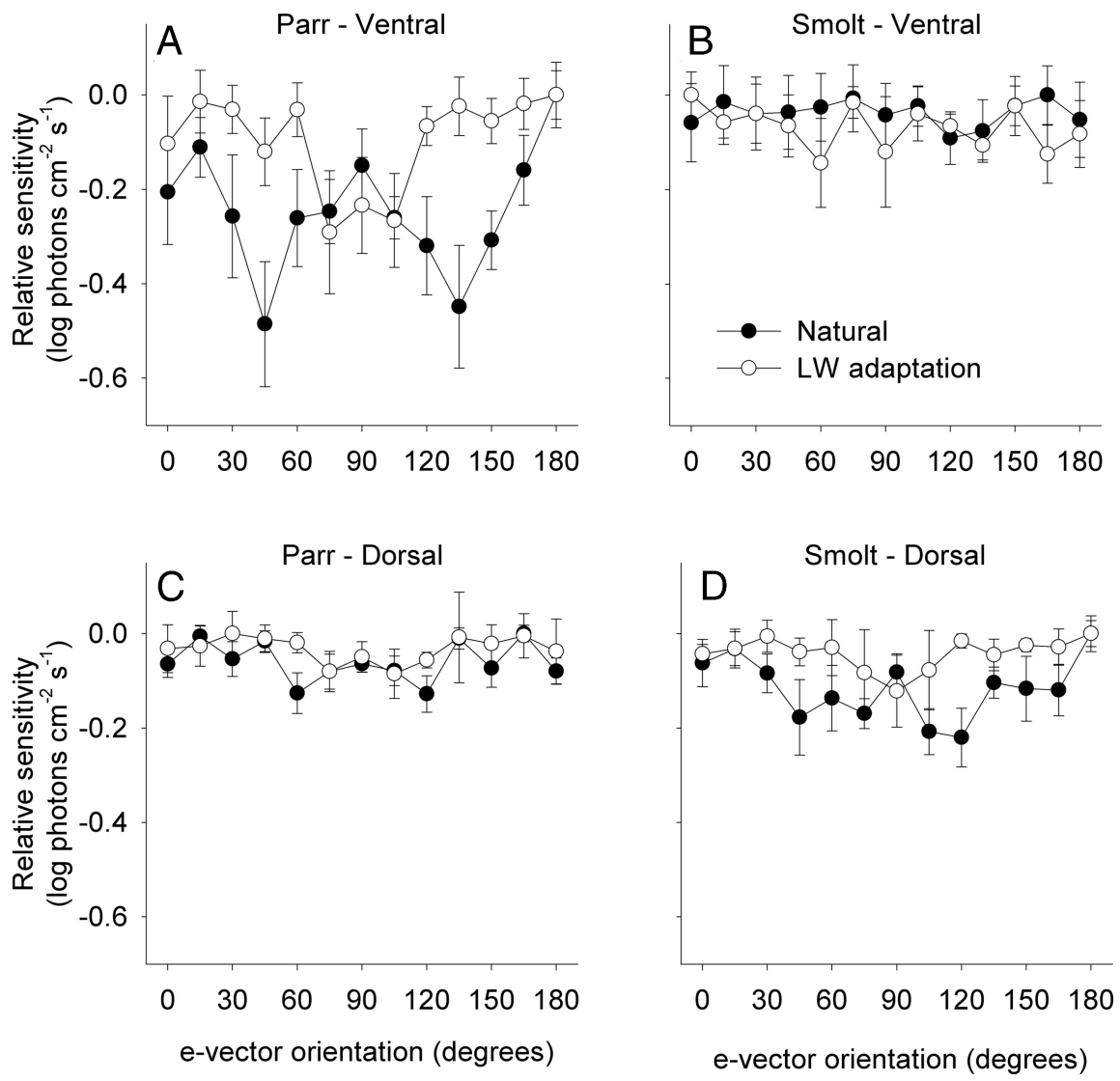

Figure 4. Effect of modulation of background illumination on PS varies across the retina and during ontogeny of rainbow trout. PS measured under natural and LW adaptation backgrounds with polarized-light stimuli at a wavelength of $360 \mathrm{~nm}$. $\boldsymbol{A}, \boldsymbol{D}$, PSFs in the ventral retina of parr and the dorsal retina of smolts reacted robustly and similarly to background modulation. $B, C, P S F s$ in the dorsal retina of parr and the ventral retina of smolts reacted minimally to background modulation. Error bars indicate $\pm 1 \mathrm{SEM}$. Sample size, natural background: parr-dorsal: $n=12$, parr-ventral: $n=11$, smolt-dorsal: $n=12$, smolt-ventral: $n=10$; LW adaptation background: parr-dorsal: $n=6$, parr-ventral: $n=6$, smolt-dorsal: $n=5$, smolt-ventral: $n=4$.

retina of smolts, exhibited substantial UVS contribution (Fig. $5 A-D)$.

To quantify the contributions of the UVS and LWS pathways to spectral sensitivity, we calculated the ratio between the sensitivity at $360 \mathrm{~nm}$ and the average sensitivity across the 640-680 $\mathrm{nm}$ range (hereafter referred to as the LWS:UVS ratio or LUR; the higher the ratio, the larger is the relative contribution of the LWS cone). These wavelengths correspond to the wavelengths of maximum sensitivity of the UVS $(\sim 360 \mathrm{~nm})$ and LWS $(\sim 670 \mathrm{~nm})$ when the cone pathways interact, as measured from an intact retina (Browman and Hawryshyn, 1994). The exact cone contribution depends on the background used; however, because the sensitivity of all groups was measured under the same two backgrounds, a clear pattern of differentiation between retina regions and life stages emerged.

LWS:UVS ratio in smolts was significantly higher than in parr for both the ventral and dorsal retina (Fig. $5 E$ ). This was true under the natural background (RT, ventral: $p=0.024 ; \mathrm{LUR}_{\mathrm{parr}}=$ $1.39 \pm 1.23, \mathrm{LUR}_{\mathrm{smolt}}=4.25 \pm 2.67$ average $\pm \mathrm{SD} ; n_{\mathrm{parr}}=7$, $n_{\text {smolt }}=5$; dorsal: $p=0.050 ; \mathrm{LUR}_{\text {parr }}=0.29 \pm 0.30, \mathrm{LUR}_{\text {smolt }}=$ $\left.0.73 \pm 0.36 ; n_{\text {parr }}=5, n_{\text {smolt }}=7\right)$, but not under the LW adaptation background that, as expected, reduced any differences observed in LUR (RT, ventral: $p=0.089$; $\mathrm{LUR}_{\text {parr }}=0.36 \pm 0.21$, $\mathrm{LUR}_{\text {smolt }}=3.38 \pm 2.92 ; n_{\text {parr }}=3, n_{\text {smolt }}=4$; dorsal: $p=0.150$; $\mathrm{LUR}_{\text {parr }}=0.21 \pm 0.14, \mathrm{LUR}_{\text {smolt }}=0.39 \pm 0.22 ; n_{\text {parr }}=5, n_{\text {smolt }}$ $=6)$. LWS:UVS ratio differences between parr and smolts could not be attributed to ontogenetic differences in the transmission of the ocular media that were approximated by the transmission of the lens in rainbow trout (Hawryshyn et al., 1989) and were negligible (Fig. $5 F$ ). In addition, LWS:UVS ratio in the ventral retina was significantly higher than in the dorsal retina under both backgrounds for smolts, but only under the natural background for parr, supporting the qualitative analysis of sensitivity spectra presented above (RT, parr natural: $p=0.034 ; \mathrm{LUR}_{\mathrm{ventral}}=1.39 \pm$ $1.23, \mathrm{LUR}_{\text {dorsal }}=0.29 \pm 0.30 ; n_{\text {ventral }}=$ 7 , $n_{\text {dorsal }}=5$; parr LW adaptation: $p=0.271 ;$ LUR $_{\text {ventral }}=0.36 \pm 0.21$, LURdorsal $=0.21 \pm 0.14 ; n_{\text {ventral }}=3, n_{\text {dorsal }}=5$; smolt natural: $p=0.002 ; \mathrm{LUR}_{\text {ventral }}=$ $4.25 \pm 2.67, \mathrm{LUR}_{\text {dorsal }}=0.73 \pm 0.36 ; n_{\mathrm{ven}}{ }^{-}$ tral $=5, n_{\text {dorsal }}=7$; smolt LW adaptation: $p=0.005 ; \mathrm{LUR}_{\text {ventral }}=3.38 \pm$ $2.92, \mathrm{LUR}_{\text {dorsal }}=0.39 \pm 0.22 ; n_{\text {ventral }}=$ $4, n_{\text {dorsal }}=6$ ). These data indicate three aspects of variation in spectral sensitivity across retinal regions and life stages: (1) the LWS:UVS ratio in the ventral retina was higher than in the dorsal retina for both parr and smolts, (2) the LWS:UVS ratio in both the ventral and dorsal retina was higher in smolts than in parr, and (3) the UVS contribution was evident in the dorsal and ventral retina of parr, but only in the dorsal retina of smolts (Fig. $5 G$ ).

\section{Association between cone contributions and the characteristics of PS}

Integration of polarization and spectral sensitivity results revealed important association patterns. First, the absence of PS in the ventral retina of smolts was associated with the lack of UVS contribution to spectral sensitivity. Second, excluding the ventral retina of smolts (that did not show PS), the amplitude of PSF was correlated with the LWS:UVS ratio (Fig. 5H). Therefore, differential contributions of the UVS and LWS pathways to spectral sensitivity may explain the variation in the amplitude of PSF; and the lack of UVS contribution to spectral sensitivity may explain the absence of PS in the ventral retina of smolts. Nevertheless, variation in the contribution of the UVS and LWS pathways could not fully account for the variation in the shape of PSF.

\section{Effect of feedback from horizontal cells to cones on PS}

Feedback from retinal interneurons such as HCs may also shape PS. PSFs may show intermediary sensitivity peaks in addition to the main sensitivity peaks to vertical $\left(\mathrm{eV} 0^{\circ}, 180^{\circ}\right)$ and horizontal $\left(\mathrm{eV} 90^{\circ}\right)$ polarization. These peaks shift with respect to $\mathrm{eV}$ depending on background illumination and are eliminated as feedback from HCs to cones is inhibited (Ramsden et al., 2008). This suggests a role for an outer retinal neuronal feedback loop in tuning PS (Kamermans and Hawryshyn, 2011). To investigate how $\mathrm{HC}$-cone feedback tunes PS and whether it varies across the retina and during ontogeny, we further developed a cascade retinal model for PS (Kamermans and Hawryshyn, 2011) and fit it to the data. (See Materials and Methods for a description of the 

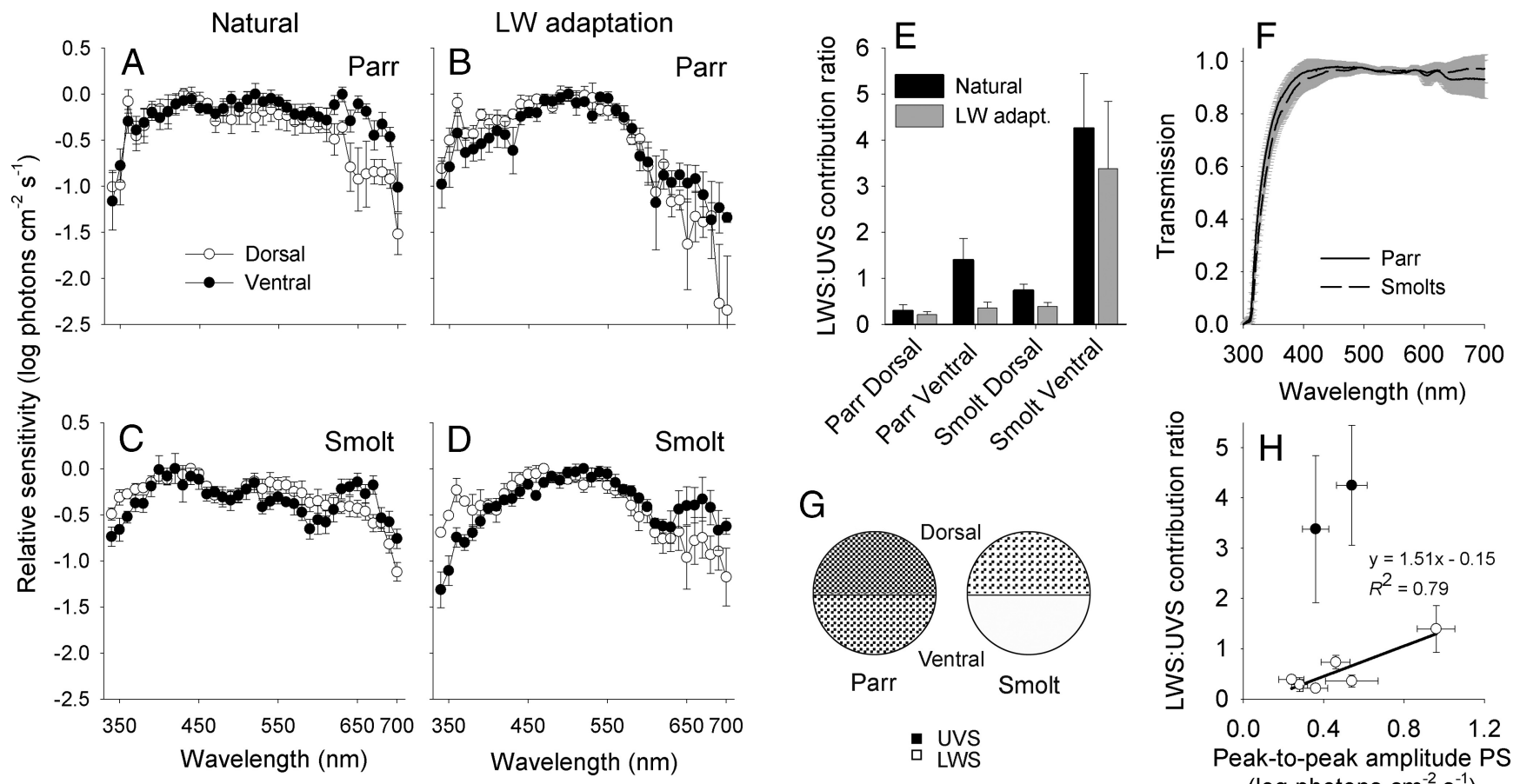

Figure 5. Topography of spectral sensitivity changes during ontogeny of rainbow trout. $A-D$, Spectral sensitivity of the dorsal and ventral retina in parr and smolts and under two background conditions. LWS cone-mediated LW sensitivity was higher in the ventral than in the dorsal retina for both parr and smolts under both backgrounds. $A, B$, In parr, UV sensitivity peaks ( $360 \mathrm{~nm}$ ) were evident for the dorsal and ventral retina and under both backgrounds; therefore, these peaks reflect the sensitivity of UVS cones. $C, D$, In smolts, UV sensitivity under the natural background was higher in the dorsal than in the ventral retina. However, when switching from the natural to LW adaptation background, UV sensitivity increased for the dorsal retina but decreased for the ventral retina. Therefore, UV sensitivity in the dorsal retina of smolts reflects the sensitivity of UVS cones, whereas in the ventral retina, it mainly reflects the sensitivity of the $\beta$-band of longer wavelength sensitive cones. Therefore, both the dorsal and ventral retina of parr, but only the dorsal retina of smolts, exhibited substantial UVS contribution. Error bars indicate \pm 1 SEM. Sample size, natural background: parr-dorsal: $n=5$, parr-ventral: $n=7$, smolt-dorsal: $n=7$, smolt-ventral: $n=6$; LW adaptation background: parr-dorsal: $n=5$, parr-ventral: $n=4$, smolt-dorsal: $n=6$, smolt-ventral: $n=4$. E, The relative contributions of the UVS and LWS pathways to spectral sensitivity (LWS:UVS ratio or LUR) in smolts was higher than in parr for the ventral and dorsal retina (see Results for statistics). In addition, the LWS:UVS ratio under the LW adaptation background was slightly lower than under the natural background for all retinal regions and life stages, confirming that the LW adaptation background indeed selectively adapted the LWS pathway. Error bars indicate \pm 1 SEM. Sample size as in $\boldsymbol{A}-\boldsymbol{D}$, except for parr-ventral under LW adaptation $(n=3)$ and smolt-ventral under natural $(n=5)$, where one repetition was missing sensitivity data at $360 \mathrm{~nm}$, precluding the calculation of LUR. $F$, Spectral lens transmission of parr $(n=5)$ and $\operatorname{smolts}(n=$ 8) was similar. Error bars indicate \pm 1 SD. G, Schematic showing how the relative contributions of the UVS (black pixels) and LWS (white pixels) pathways to spectral sensitivity vary across retinal regions and life stages. For example, the white area in the ventral retina of smolts indicates the contribution of LWS but not of UVS. $\boldsymbol{H}$, Excluding the ventral retina of smolts (which did not show PS; $n=2$; black symbols), PSF amplitude was correlated with the relative contribution of the LWS pathway to spectral sensitivity (Pearson $r=0.879, p=0.021, n=6$ ). Bidirectional error bars indicate \pm 1 SEM. Sample size for LUR similar to that in E. Sample size for AMP, natural background: parr-dorsal: $n=12$, parr-ventral: $n=11$, smolt-dorsal: $n=12$, smolt-ventral: $n=10$; LW adaptation background: parr-dorsal: $n=6$, parr-ventral: $n=6$, smolt-dorsal: $n=5$, smolt-ventral: $n=4$.

model.) Fitting such a basic model to PS data can give us some insight into the gross processes underlying PS, but it cannot provide us with a definite role of the various retinal elements and processes. Nonetheless, in general, PS data could be described reasonably well by the model. Figure 6 shows example polarization tuning functions for the various model components and Table 1 provides detailed model parameter estimates. The worst fits were obtained for the ventral retina of smolts, in which we observed PS to be low or completely absent, and for the dorsal retina of parr, in which PSFs measured under the natural background showed multiple intermediary sensitivity peaks (Fig. 7A$H)$. This was also evident by the normalized rms error between data and model (Fig. 7I). In all cases, the ratio between the estimated weight of the vertical and horizontal detectors $\left(K_{\mathrm{Pv}} / K_{\mathrm{Ph}}\right)$ was higher under the LW adaptation background than under the natural background, supporting the notion that the UVS pathway constitutes the vertical polarization detector and the LWS/ MWS pathway constitutes the horizontal polarization detector (Fig. 7J). Finally, estimated HC-cone feedback varied between retinal regions, with the relationship between the estimated feedback obtained under the two backgrounds varying between retinal regions (Fig. $7 K$ ). Specifically, feedback under the natural background was lower than under the LW adaptation for the ventral retina of parr and the dorsal retina of smolts. In contrast, feedback under the natural background was higher than under the LW adaptation for the dorsal retina of parr and the ventral retina of smolts. This supports our observation that PS in the ventral retina of parr resembles that in the dorsal retina of smolts.

\section{Discussion}

Effect of differential contribution of polarization pathways and neural feedback on PS

PS in rainbow trout varied across the retina and during ontogeny, showing a switch in the retinal region of enhanced PS from the ventral retina in parr to the dorsal retina in smolts. Differential contribution of two polarization pathways was directly associated with differences in PS between retinal regions and life stages. First, UVS cones were reported to be present across the whole retina of parr rainbow trout, but only in the dorsotemporal retina of smolts (Beaudet et al., 1993; Allison et al., 2003). The effect of selective disappearance of UVS cones on PS in smolts was tested in the present study. We found that PS in the ventral retina of smolts was asymmetric around $\mathrm{eV} 90^{\circ}$ and varied minimally with background modulation, suggesting the lack of PS. Therefore, the lack of PS in the 

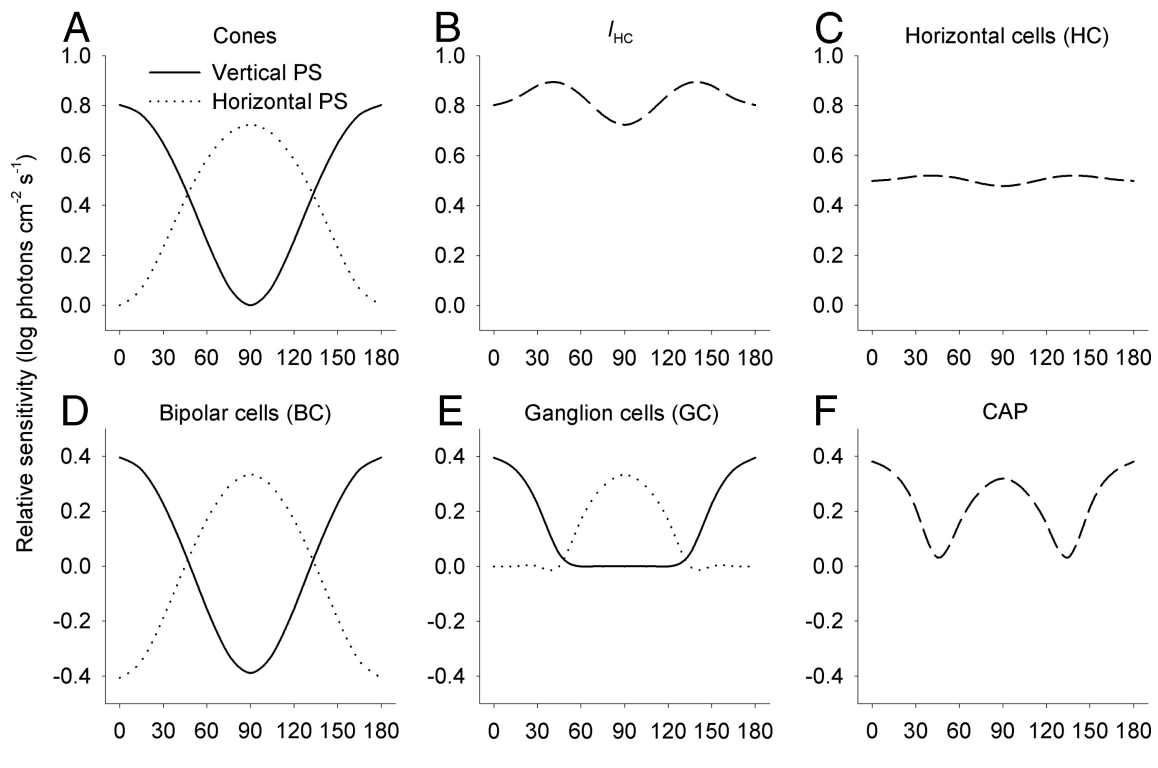

Figure 6. Example of $P S$ functions for various components of the retinal model for $P S$. eV tuning curves modeled for the cone photoreceptors $(\boldsymbol{A})$, total activity of horizontal cells $(\boldsymbol{B})$, output of horizontal cells $(\boldsymbol{C}$ ), bipolar cells $(\boldsymbol{D}), \mathrm{GCs}(\boldsymbol{E})$, and CAP $(\boldsymbol{F})$. The model parameters used in this example are those estimated for the ventral retina of parr under natural background: $K_{\mathrm{Pv}}=2.665$, $K_{\mathrm{Ph}}=2.403, B=-0.227, \mathrm{C}=0.816, K=0.304$.

Table 1. Parameter estimates of the retinal model for polarization sensitivity

\begin{tabular}{llllllll}
\hline Life stage & Retinal region & Background & $K_{\mathrm{Pv}}$ & $K_{\mathrm{Ph}}$ & $B$ & $C$ & $K$ \\
\hline Parr & \multirow{2}{*}{ Dorsal } & Natural & 0.867 & 0.711 & -0.987 & 3.963 & 0.001 \\
& & LW adaptation & 0.876 & 0.706 & -2.828 & 0.008 & 3.425 \\
& \multirow{4}{*}{ Sentral } & Natural & 2.665 & 2.403 & -0.227 & 0.816 & 0.304 \\
& & LW adaptation & 2.684 & 1.964 & -1.098 & 3.459 & 0.002 \\
& Dorsal & Natural & 3.423 & 2.977 & -0.308 & 1.038 & 1.223 \\
& & LW adaptation & 1.429 & 1.097 & -1.131 & 3.032 & 0.009 \\
& \multirow{2}{*}{ Ventral } & Natural & 0.271 & 0.568 & -0.060 & 1.361 & 1.904 \\
& & LW adaptation & 0.227 & 0.113 & -0.024 & 0.142 & 0.177 \\
\hline
\end{tabular}

ventral retina of smolts was associated with reduction of UVS contribution to spectral sensitivity (this study) and with the absence of UVS cones in the ventral retina (Beaudet et al., 1993; Allison et al., 2003), demonstrating the key role of UVS cones in PS.

Second, greater PSF amplitudes were associated with greater LWS:UVS ratios. This held for intermediate ratio values (0.211.39 , as observed in the dorsal and ventral retina of parr and the dorsal retina of smolts). However, larger LWS:UVS ratios (3.384.25 , as observed in the ventral retina of smolts) corresponding to lower contributions of the UVS pathway were associated with the lack of PS. Indeed, PS in the ventral retina measured with the UVS pathway chromatically isolated disappeared in smolts; however, when measured with the LWS pathway chromatically isolated, PS showed symmetry around $\mathrm{eV} 90^{\circ}$ and an amplitude even larger than in parr (Parkyn and Hawryshyn, 1993). That is, smoltification was associated with reduction in the contribution of the UVS pathway in the ventral retina, but with retention or even an increase in the contribution of the LWS pathway, which is consistent with our findings. Therefore, our results highlight the importance of well balanced contributions of the LWS and UVS pathways to allow for PS. At intermediate LWS:UVS ratios, reduction of LWS contribution could explain the reduction in PSF amplitude in the dorsal retina of parr and the dorsal retina of smolts compared with the ventral retina of parr. Therefore, differential contribution of the UVS and LWS pathways can partly account for the variation observed in the PSF amplitude across the retina and life stages.

Furthermore, this study suggests that variation in $\mathrm{HC}$ - cone feedback could further explain the variation observed in PS. The role of $\mathrm{HC}$-cone feedback in tuning PS may be studied directly by measuring PS under the blockade of feedback (e.g., using cobalt chloride;Fahrenfort et al., 2004) and again when feedback is allowed. Instead, in this study, we further developed a retinal model for PS and fit it to data. Although not direct, this approach may provide insight into how neural feedback tunes PS. The effect of background modulation on the estimated feedback was similar for the ventral retina of parr and the dorsal retina of smolts and differed from that for the dorsal retina of parr and the ventral retina of smolts. This is consistent with the similarity in PSF shape observed between the ventral retina of parr and the dorsal retina of smolts, indicating that variation in PS could be partly explained by differential $\mathrm{HC}$-cone feedback.

\section{Possible mechanism for PS in vertebrates}

Variation in the contribution of two orthogonal polarization pathways and in HC-cone feedback was associated with the variation observed in PS between retinal regions and life stages. Based on these findings, we propose that PS in rainbow trout depends, at least partly, on weak PS of the UVS cone (mediating vertical PS) and the MWS/LWS cones (mediating horizontal PS) and on feedback from horizontal cells to cones. The weak PS of cones might arise from small axial dichroism in individual cones (Roberts and Needham, 2007) and/or from transverse dichroism from reflection off the partitioning membrane of double cones in the regularly arranged square cone mosaic (Flamarique et al., 1998). This initial differential PS produced at the photoreceptors is then amplified at the synapse between horizontal cells and cones due to the nonlinearity of horizontal cells. This elegant arrangement, in which most PS amplification and tuning are performed by retinal networks, allows cones to show only a small level of PS, and thus allows for PS without interfering with sampling of other aspects of visual information, such as color, which are mediated by the same cones.

\section{Possible significance for ontogenetic switch in PS between retinal regions}

The ability to orient in space is a hallmark of the life history of salmonids (Groot, 1965), in which both vision and olfaction are central for efficient orientation (Groves et al., 1968). The habitat type and depth where orientation is performed vary considerably throughout ontogeny. parr salmonids move between shallow $(<1 \mathrm{~m})$ freshwater feeding grounds (Heggenes and Saltveit, 1990; Heggenes, 1990). Smolts migrate from freshwater to marine habitats (in anadromous populations) or to deep $(>10 \mathrm{~m})$ freshwater habitats (in land-locked populations) and thereafter migrate between deep feeding and wintering grounds (Groot, 1965; Brannon and Salo, 1981; Healey, 1991). Finally, adult salmonids return to their 

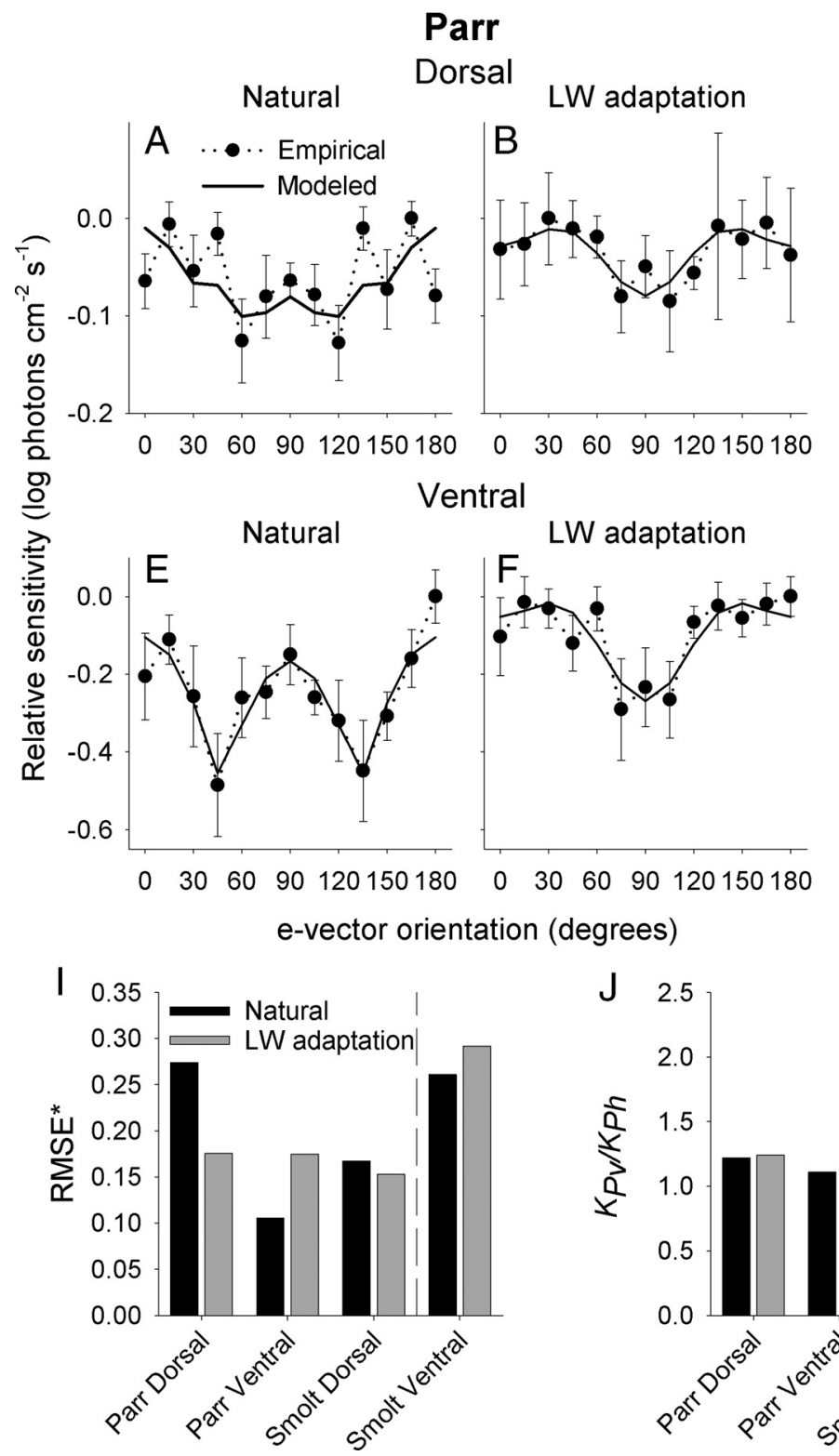
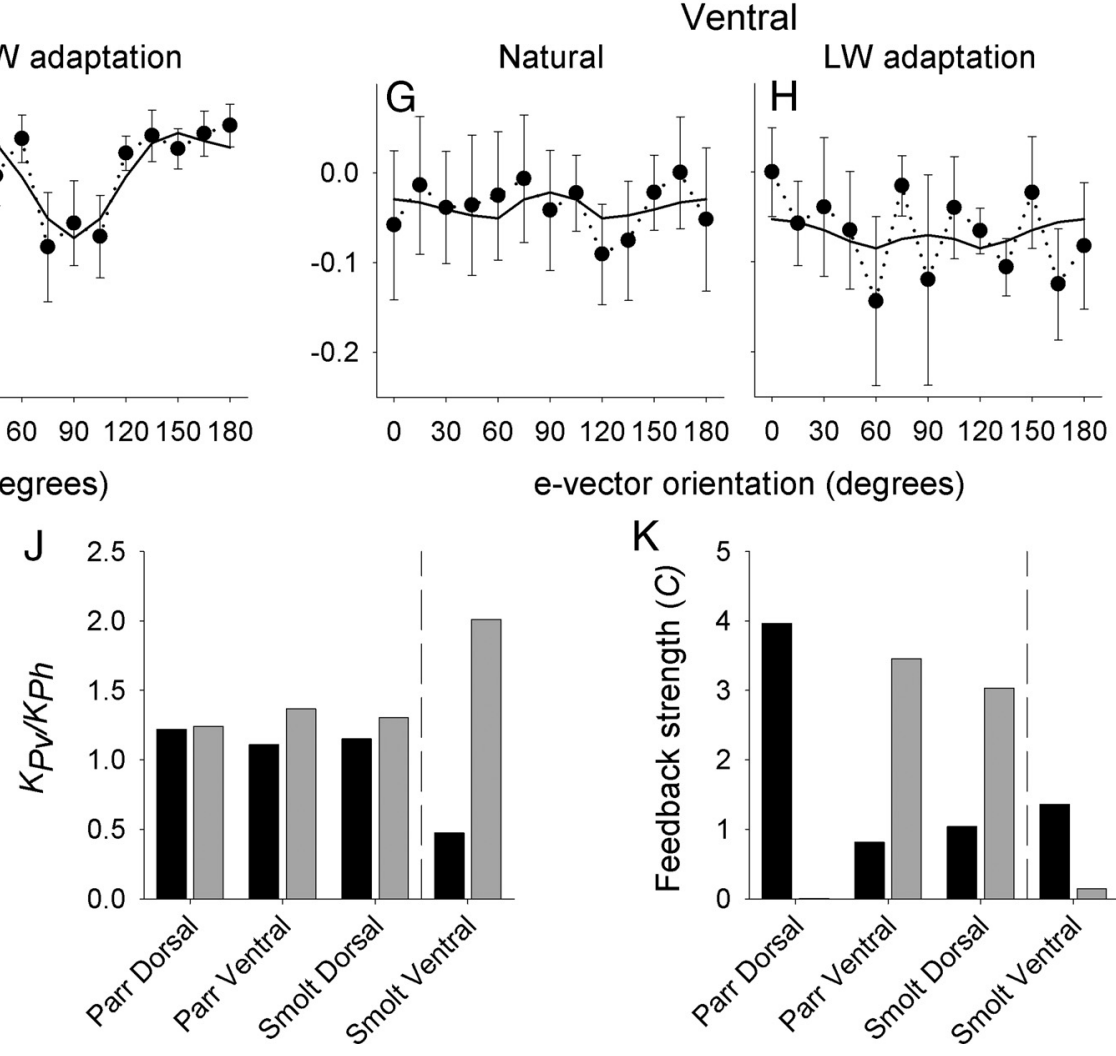

\section{Smolt Dorsal}
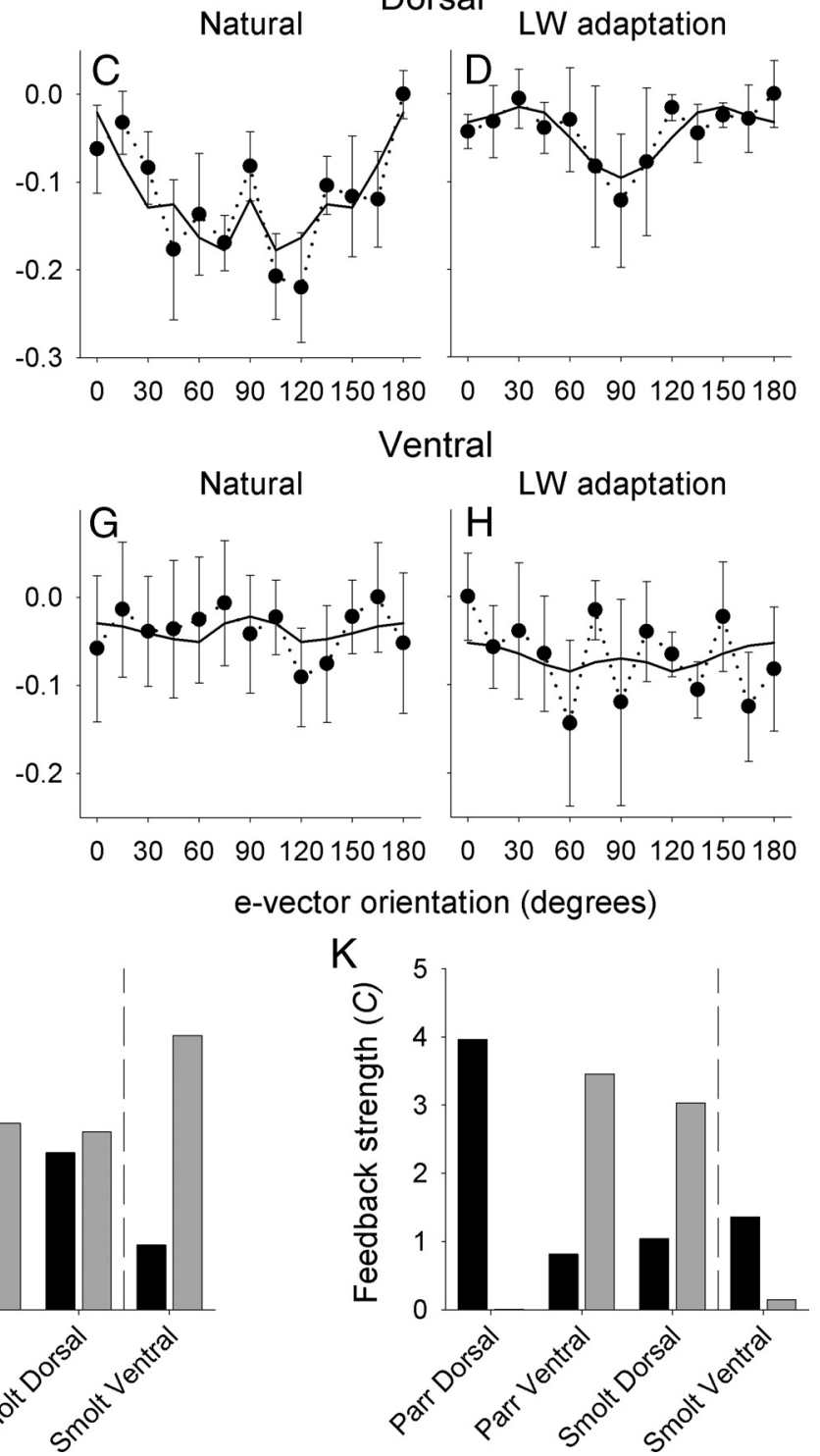

Figure 7. Retinal model for PS in rainbow trout. $\boldsymbol{A}-\boldsymbol{H}$, PSF for the dorsal and ventral retina in parr and smolts under two backgrounds were fit to a retinal model for PS. Generally, the retinal model fit the empirical PSF well. Exceptions are PSFs of the dorsal retina of parr under natural background $(\boldsymbol{A})$, which showed multiple intermediary sensitivity peaks, and PSFs of the ventral retina in smolts, which were asymmetrical around $\mathrm{eV} 90^{\circ}(\mathbf{G}, \mathbf{H})$. The scale of the sensitivity axis is similar for pairs measured under the two backgrounds, but different between measurement pairs. Error bars indicate \pm 1 SEM. I, The normalized rms error (RMSE*) between the empirical and modeled sensitivity (RMSE normalized to the amplitude of empirical PSF). RMSE* for the dorsal retina of parr (under natural background) and for the ventral retina of smolts (separated by a dashed vertical line) was larger than for the other groups. $J$, The ratio between the estimated weight of the vertical and horizontal detectors $\left(K_{\mathrm{Pv}} / K_{\mathrm{ph}}\right)$ was higher under the LW adaptation background than under the natural background. $\boldsymbol{K}$, Estimates of HC - cone feedback (model parameter $C$ ). For both the ventral retina in parr and the dorsal retina in smolts, C behaved similarly when switching between PS measured under the two backgrounds. In contrast, for the dorsal retina in parr and the ventral retina of smolts, $C$ changed in an opposite manner when switching between PS measured under the two backgrounds.

natal steam to spawn and die while swimming in shallow water $(<1$ m; Ruggerone et al., 1990; Sturlaugsson and Tórisson, 1995).

To evaluate the ecological significance of the observed ontogenetic switch in the retinal region of enhanced PS, one should first consider the polarization patterns available in the natural environment. Two distinct light polarization fields are encountered under water: (1) the celestial polarization field that is refracted at the water surface and transmitted within Snell's window (Sabbah et al., 2006) and (2) the underwater polarization field that is found outside of Snell's window and originates mainly from scattering by water molecules and particulate matter (Waterman, 1954; Sabbah et al., 2005).
The shallow-swimming parr are able to orient relative to polarized light patterns that are incident from above and illuminate the ventral retina (Hawryshyn and Bolger, 1990; Hawryshyn et al., 1990; Degner and Hawryshyn, 2001; Parkyn et al., 2003), suggesting that parr may use the celestial polarization pattern for orientation. In contrast, smolts reside in deeper water, where the celestial polarization pattern becomes distorted and unreliable due to polarization decay when celestial light is transmitted through water. The rate of polarization decay increases with scattering in the media, with only $10 \%$ of the initial polarization remaining after being transmitted 4 and $10 \mathrm{~m}$ in partially turbid and clear water, respectively (Shashar et al., 2004). Therefore, PS 
in the ventral retina is expected to be disadvantageous and thus to disappear when parr transform into smolts, an idea supported by a past study (Hawryshyn et al., 1990). Interestingly, instead of using the unreliable celestial pattern for orientation at deep water, smolts may use the relatively depth-insensitive underwater polarization pattern found outside of Snell's window (Waterman, 1955; Tyler, 1963). This pattern is most stable at depressed lines of sight (viewing zenith angles $>90^{\circ}$; Sabbah and Shashar, 2006,2007 ) and would be projected on the dorsotemporal retina of smolts. Therefore, to ensure the detection of accurate polarization orientation cues, PS in rainbow trout would expect to switch from the ventral retina to the dorsotemporal retina upon smoltification. This expectation is in agreement with our findings. Moreover, the shallow-swimming adult rainbow and steelhead trout were suggested to regain PS in the ventral retina (Allison et al., 2003), which supports our suggestion of a relation between the retinal region of enhanced PS, polarized-light pattern used, and habitat depth. We propose that the variation in PS across the retina and during ontogeny may reflect a visual adaptation that may allow using the most reliable polarization field encountered at each life stage: the celestial polarization field in the shallowswimming parr versus the underwater polarization field in the deep-swimming smolts. However, some land-locked trout populations are not strictly migratory but still show PS, suggesting that PS might be used for tasks other than orientation. Indeed, polarized-light cues may help rainbow trout parr in detecting zooplanktonic prey (Flamarique and Browman, 2001). It is unknown which retinal region is used for foraging in parr and whether foraging in smolts uses the same retinal region or would favor a switch in the retinal region of PS.

\section{Complex PS in the dorsal retina of rainbow trout parr}

PSFs in the dorsal retina of parr had a significantly smaller amplitude compared with both the ventral retina of parr and the dorsal retina of smolts; however, these PSFs had a symmetric and complex shape with multiple secondary sensitivity peaks, a shape that deviated from the classic two-pathway-mediated, w-shaped PSFs and could not be accurately reproduced by the retinal model proposed. These findings might suggest the presence of a sophisticated, high $\mathrm{eV}$ resolution, PS system as yet unexplored that might be used in polarization-based foraging and communication.

\section{References}

Allison WT, Dann SG, Helvik JV, Bradley C, Moyer HD, Hawryshyn CW (2003) Ontogeny of ultraviolet-sensitive cones in the retina of rainbow trout (Oncorhynchus mykiss). J Comp Neurol 461:294-306. CrossRef Medline

Baylor DA, Fuortes MG, Obryan PM (1971) Receptive fields of cones in retina of turtle. J Physiol 214:265-294. Medline

Beaudet L, Browman HI, Hawryshyn CW (1993) Optic nerve response and retinal structure in rainbow trout of different sizes. Vision Res 33:17391746. CrossRef Medline

Brannon EL, Salo EO, eds (1981) Proceedings of the salmon and trout migratory behavior symposium. Seattle: University of Washington.

Browman HI, Hawryshyn CW (1992) Thyroxine induces a precocial loss of ultraviolet photosensitivity in rainbow trout (Oncorhynchus mykiss, Teleostei). Vision Res 32:2303-2312. CrossRef Medline

Browman HI, Hawryshyn C (1994) Retinoic acid modulates retinal development in the juveniles of a teleost fish. J Exp Biol 193:191-207. Medline

Cheng CL, Flamarique IN, Hárosi FI, Rickers-Haunerland J, Haunerland NH (2006) Photoreceptor layer of salmonid fishes: Transformation and loss of single cones in juvenile fish. J Comp Neurol 495:213-235. CrossRef Medline

Coughlin DJ, Hawryshyn CW (1995) A cellular basis for polarized-light vision in rainbow trout. J Comp Physiol A Neuroethol Sens Neural Behav Physiol 176:261-272.
Degner SL, Hawryshyn CW (2001) Orientation of rainbow trout (Oncorhynchus mykiss) to multiple patches of linearly polarized light. Can J Zool 79:407-415.

Edgington ES (1995) Randomization Tests. New York: Marcel-Dekker.

Fahrenfort I, Sjoerdsma T, Ripps H, Kamermans M (2004) Cobalt ions inhibit negative feedback in the outer retina by blocking hemichannels on horizontal cells. Vis Neurosci 21:501-511. CrossRef Medline

Flamarique IN, Browman HI (2001) Foraging and prey-search behaviour of small juvenile rainbow trout (Oncorhynchus mykiss) under polarized light. J Exp Biol 204:2415-2422. Medline

Flamarique IN, Hendry A, Hawryshyn CW (1992) The photic environment of a salmonid nursery lake. J Exp Biol 169:121-141.

Flamarique IN, Hawryshyn CW, Hárosi FI (1998) Double-cone internal reflection as a basis for polarization detection in fish. J Opt Soc Am A 15:349-358. CrossRef

Forward RB, Waterman TH (1973) Evidence for $e$-vector and light intensity pattern discrimination by the teleost Demogenys. J Comp Physiol A Neuroethol Sens Neural Behav Physiol 87:189-202. CrossRef

Govardovskii VI, Fyhrquist N, Reuter T, Kuzmin DG, Donner K (2000) In search of the visual pigment template. Vis Neurosci 17:509-528. CrossRef Medline

Groot C (1965) On the orientation of young sockeye salmon (Oncorhynchus nerka) during their seaward migration out of lakes. Behaviour 14(suppl.): 198.

Groves AB, Collins GB, Trefethen PS (1968) Roles of olfaction and vision in choice of spawning site by homing adults chinook salmon (Oncorhynchus tshawytscha). J Fish Res Board Can 25:867-876. CrossRef

Hárosi FI (1994) An analysis of two spectral properties of vertebrate visual pigments. Vision Res 34:1359-1367. CrossRef Medline

Hawryshyn CW (2010) Ultraviolet polarization vision and visually guided behavior in fishes. Brain Behav Evol 75:186-194. CrossRef Medline

Hawryshyn CW, Bolger AE (1990) Spatial orientation of trout to partially polarized-light. J Comp Physiol A Neuroethol Sens Neural Behav Physiol 167:691-697.

Hawryshyn CW, Hárosi FI (1994) Spectral characteristics of visual pigments in rainbow trout (Oncorhynchus mykiss). Vision Res 34: 1385-1392. CrossRef Medline

Hawryshyn CW, Arnold MG, Chaisson DJ, Martin PC (1989) The ontogeny of ultraviolet photosensitivity in rainbow trout (Salmo gairdneri). Vis Neurosci 2:247-254. CrossRef Medline

Hawryshyn CW, Arnold MG, Bowering E, Cole RL (1990) Spatial orientation of rainbow trout to plane-polarized light-the ontogeny of $e$-vector discrimination and spectral sensitivity characteristics. J Comp Physiol A Neuroethol Sens Neural Behav Physiol 166:565-574.

Hawryshyn CW, Moyer HD, Allison WT, Haimberger TJ, McFarland WN (2003) Multidimensional polarization sensitivity in damselfishes. J Comp Physiol A Neuroethol Sens Neural Behav Physiol 189: 213-220. Medline

Healey MC (1991) Life history of chinook salmon (Oncorhynchus tshcrwytscha). In: Pacific salmon life histories (Groot C, Margolis L, eds), pp 311394. Vancouver: UBC.

Heggenes J (1990) Habitat utilization and preferences in juvenile Atlantic salmon Salmo salar in streams. Regul Rivers: Res Manage 5:341-354. CrossRef

Heggenes J, Saltveit SJ (1990) Seasonal and spatial microhabitat selection and segregation in young atlantic salmon, Salmo salar L, and brown trout, Salmo trutta L, in a Norwegian river. J Fish Biol 36:707-720. CrossRef

Horváth G, Varjú D (2004) Polarized light in animal vision: Polarization patterns in nature. Heidelberg: Springer.

Kamermans M, Hawryshyn C (2011) Teleost polarization vision: how it might work and what it might be good for. Philos Trans R Soc Lond B 366:742-756. CrossRef

Kleerekoper H, Matis JH, Timms AM, Gensler P (1973) Locomotor response of goldfish to polarized-light and its $e$-vector. J Comp Physiol 86:27-36. CrossRef

Parkyn DC, Hawryshyn CW (1993) Polarized-light sensitivity in rainbow trout (Oncorhynchus mykiss) - Characterization from multiunit responses in the optic nerve. J Comp Physiol A Neuroethol Sens Neural Behav Physiol 172:493-500. CrossRef

Parkyn DC, Hawryshyn CW (2000) Spectral and ultraviolet-polarisation sensitivity in juvenile salmonids: A comparative analysis using electrophysiology. J Exp Biol 203:1173-1191. Medline 
Parkyn DC, Austin JD, Hawryshyn CW (2003) Acquisition of polarizedlight orientation in salmonids under laboratory conditions. Anim Behav 65:893-904. CrossRef

Ramsden SD, Anderson L, Mussi M, Kamermans M, Hawryshyn CW (2008) Retinal processing and opponent mechanisms mediating ultraviolet polarization sensitivity in rainbow trout (Oncorhynchus mykiss). J Exp Biol 211:1376-1385. CrossRef Medline

Roberts NW, Needham MG (2007) A mechanism of polarized light sensitivity in cone photoreceptors of the goldfish Carassius auratus. Biophys J 93:3241-3248. CrossRef Medline

Ruggerone GT, Quinn TP, McGregor IA, Wilkinson TD (1990) Horizontal and vertical movements of adult steelhead trout, Oncorhynchus mykiss, in the Dean and Fisher channels, British Columbia. Can J Fish Aquat Sci 47:1963-1969. CrossRef

Sabbah S, Shashar N (2006) Underwater light polarization and radiance fluctuations induced by surface waves. Appl Opt 45:4726-4739. CrossRef Medline

Sabbah S, Shashar N (2007) Light polarization under water near sunrise. J Opt Soc Am A 24:2049-2056. CrossRef

Sabbah S, Lerner A, Erlick C, Shashar N (2005) Under water polarization vision- A physical examination. In: Recent Research Developments in Experimental and Theoretical Biology (Pandalai SG, ed), pp 123-177. Trivandrum: Transworld Research Network.

Sabbah S, Barta A, Gal J, Horvath G, Shashar N (2006) Experimental and theoretical study of skylight polarization transmitted through Snell's window of a flat water surface. J Opt Soc Am A 23:1978-1988. CrossRef

Sabbah S, Lamela Laria R, Gray SM, Hawryshyn CW (2010) Functional di- versity in the color vision of cichlid fishes. BMC Biol 8:33. CrossRef Medline

Sabbah S, Gray SM, Boss ES, Fraser JM, Zatha R, Hawryshyn CW (2011) The underwater photic environment of Cape Maclear, Lake Malawi: Comparison between rock- and sand-bottom habitats and implications for cichlid fish vision. J Exp Biol 214:487-500. CrossRef Medline

Sabbah S, Hui J, Hauser FE, Nelson WA, Hawryshyn CW (2012) Ontogeny in the visual system of Nile tilapia. J Exp Biol 215:26842695. CrossRef Medline

Shashar N, Sabbah S, Cronin TW (2004) Transmission of linearly polarized light in seawater: Implications for polarization signaling. J Exp Biol 207: 3619-3628. CrossRef Medline

Sokal RR, Rohlf FJ (1995) Biometry, Ed 3. New York: Freeman.

Sturlaugsson J, Tórisson K (1995) Migration studies on homing of Atlantic Salmon (Salmo salar L.) in coastal waters W Iceland-depth movements and sea temperatures recorded at migration routes by data storage tags. Anacat Fish Committee, Annual Science Conference. Aalborg, Denmark: International Council for the Exploration of the Sea. p 13.

Tyler JE (1963) Estimation of per cent polarization in deep oceanic water. J Mar Res 21:102-109.

Waterman TH (1954) Polarization patterns in submarine illumination. Science 120:927-932. CrossRef Medline

Waterman TH (1955) Polarization of scattered sunlight in deep water. Deep-Sea Res 3:426-434.

Wolff LB, Andreou AG (1995) Polarization camera sensors. Image Vision Comput 13:497-510. CrossRef 